FERMILAB-Conf-94/340-E

\title{
Aging Tests of Ethylene Contaminated Argon/Ethane
}

\author{
M. Atac \\ Fermi National Accelerator Laboratory \\ P.O. Box 500, Batavia, Illinois 60510 \\ G. Bauer \\ Massachusetts Institute of Technology
}

September 1994 


\section{Disclaimer}

This report was prepared as an account of work sponsored by an agency of the United States Government. Neither the United States Government nor any agency thereof, nor any of their employees, makes any warranty, express or implied, or assumes any legal liability or responsibility for the accuracy, completeness, or usefulness of any information, apparatus, product, or process disclosed, or represents that its use would not infringe privately owned rights. Reference herein to any specific commercial product, process, or service by trade name, trademark, manufacturer, or otherwise, does not necessarily constitute or imply its endorsement, recommendation, or favoring by the United States Government or any agency thereof. The views and opinions of authors expressed herein do not necessarily state or reflect those of the United States Government or any agency thereof. 
CDF/DOC/TRACKING/PUBLIC/CDF/2828

\title{
Aging Tests of Ethylene Contaminated Argon/Ethane
}

\author{
M. Atac \\ Fermilab \\ G. Bauer \\ Massachusetts Institute of Technology
}

September 22, 1994

\begin{abstract}
We report on aging tests of argon/ethane gas with a minor (1800 ppm) component of ethylene. The measurements were first conducted with the addition of alcohol to test the suppression of aging by this additive, with exposure up to $\approx 1.5 \mathrm{C} / \mathrm{cm}$. Tests have included: a proportional tube with ethanol, another with isopropyl alcohol, and for comparison a tube has also been run with ethanol and argon/ethane from CDF's old (ethylene-free) ethane supply. The aging test with ethanol showed no difference between the ethylene-free and the ethylene tube. Furthermore, raw aging rates of argon/ethane and argon/ethane/ethylene were measured by exposing tubes without the addition of alcohol to about $0.1 \mathrm{C} / \mathrm{cm}$. Again, no significant difference was observed. In conclusion, we see no evidence that ethylene contamination up to $1800 \mathrm{ppm}$ has any adverse effect on wire aging. However, this level of ethylene does seem to significantly suppress the gas gain.
\end{abstract}




\section{The CDF Argon/Ethane Supply}

Most of the gas used by CDF is a 50/50 argon/ethane mixture. Last spring the facility supplying the ethane $\left(\mathrm{C}_{2} \mathrm{H}_{6}\right)$, closed down. The vendor informed CDF that the new supplies of ethane contain significant quantities of ethylene $\left(\mathrm{C}_{2} \mathrm{H}_{4}\right)$. Other vendors were contacted, and to varying degrees, also expected an ethylene component in their ethane, ranging from $1600-3000 \mathrm{ppm}[1]$. Apparently, ethylene-free ethane is no longer naturally available. However, the gas can be processed to convert the ethylene into ethane, but at additional expense.

The possible impact of few-part-per-thousand ethylene contamination is two fold: a) it may affect the gas gain and drift velocities; and more worrisome, b) its potential to promote wire aging is uncertain. In particular there have been reports of bad experiences of chamber aging with ethylene ${ }^{1}$. It has been standard practice in CDF in order to introduce small quantities of alcohol into the argon/ethane mix to suppress wire aging[2]. However the efficacy of this approach with the addition of ethylene is not certain; furthermore, (low pressure) data from plasma chemistry suggest that ethylene would be much more prone to polymerization than ethane[3]. In light of these concerns we conducted tests on ethane contaminated by ethylene.

\section{Gas Samples}

\subsection{Ethane/Ethylene}

A sample of ethylene contaminated ethane was obtained from one of the vendors, Great Lakes Airgas[4]. This gas was mixed with argon by the GowMac thermal conductivity bridge as is normally done for CDF's argon/ethane gas and stored in gas cylinders. The ethylene content of the ethane was reported to be 2,740 ppm by the vendor (see Table la in Appendix A), while for the argon/ethane mixture we found $1800 \mathrm{ppm}( \pm 450 \mathrm{ppm})$ as measured by a Dräger-Tube ${ }^{2}[5]$. An ethane/ethylene sample was also submitted to Argonne for the standard mass spectroscopic analysis that is done for all the ethane used by CDF. However, due to the overlapping pattern of ion fragments from ethane and ethylene it is very difficult to identify small quantities of ethylene in ethane by a mass spectrometer alone. Nonetheless, it is able to identify a range of other trace components. These analysis

\footnotetext{
${ }^{1} R$. Kadel has reported rapid deterioration in drift chambers using ethylene.

${ }^{2}$ The ethylene Dräger-Tube measurement is based on a chemical reaction specific to doubled bonded carbon atoms. The tube is most sensitive to, and calibrated for, ethylene; but it will respond to other such compounds. The measuring range of the tube used was from 50 to $2,500 \mathrm{ppm}$ ethylene.
} 
results are also given in Appendix A (Table 1b), the largest other contaminant seen in this analysis was oxygen at $190 \mathrm{ppm} .{ }^{3}$

\section{2 "Original Recipe" Ethane}

For comparison's sake, we have saved a sample in gas cylinders of the argon/ethane mix from the old (pre-ethylene) ethane. More specifically, a sample of gas from Tank 2, which was Mix \# 338 mixed from Trailer $388^{4}$, was preserved. We will refer to this sample as the "old ethane", or "ethylene-free" gas. A Dräger-Tube measurement did not detect any ethylene in this argon/ethane mix, i.e. less than $50 \mathrm{ppm}$. The Argonne mass spectroscopic analysis results are given in Table 2 of Appendix A.

\section{Ethylene Gain Shift}

Before the aging test began a quick check of the argon/ethane/ethylene gas gain compared to that of our normal argon/ethane mix was made using the Gas Quality Box Brandeis tubes that are normally used to monitor the gas gain for the gas calorimeters[8]. Figure 1 shows a histogram of the peak measurements from ${ }^{55} \mathrm{Fe}$ spectra for the argon/ethane/ethylene sample and for the normal gas mix used in the experiment ${ }^{5}$. The ethylene supplemented gas is found to be $6.2 \%$ lower in gain. However, it must also be noted that the Argonne analysis measured $190 \mathrm{ppm}$ of $\mathrm{O}_{2}$; and while we do not have a quantitative estimate of the gain change for this quantity of oxygen, its effect would be to also suppress the gain.

We remind the reader that the gas mixed by the Gow Mac system is based on the thermal conductivity of the gas mixtures. So it is the combined effect of the thermal conductivity and the gain of ethylene relative to argon/ethane that manifests itself as a $6.2 \%$ loss in gain. Using tabulated values of gas constants[9] and a semi-empirical relation to calculate the thermal conductivity of gas mixtures[10], one finds that the argon/ethane/ethylene mixture with $1800 \mathrm{ppm}$ ethylene which has the same conductivity as a 50/50 argon/ethane mixture is a 49.96/49.86/0.18 mix. The argon content is almost unchanged, and it is the ethane that is mostly displaced. The fairly large shift in gain for the relatively modest contamination of $1,800 \mathrm{ppm}$ indicates the ethylene has a much smaller gain relative to ethane.

\footnotetext{
${ }^{3}$ Note that the Argonne analysis tends to measure larger oxygen and water levels than are obtained by the CDF in-house ethane certification procedure; due either to additional contamination in taking and transferring the sample, or because of systematic differences in measuring techniques. The in-house CDF results tend to be favored.

${ }^{4}$ First used on-line for the detectors on May 30, 1994

${ }^{5}$ The specific gas was from Tank 1 mixed from Trailer 141 on April 18, 1994, Mix Serial \#309. This is also "ethylene-free" gas, but a different batch than that described in Section 2.2.
} 


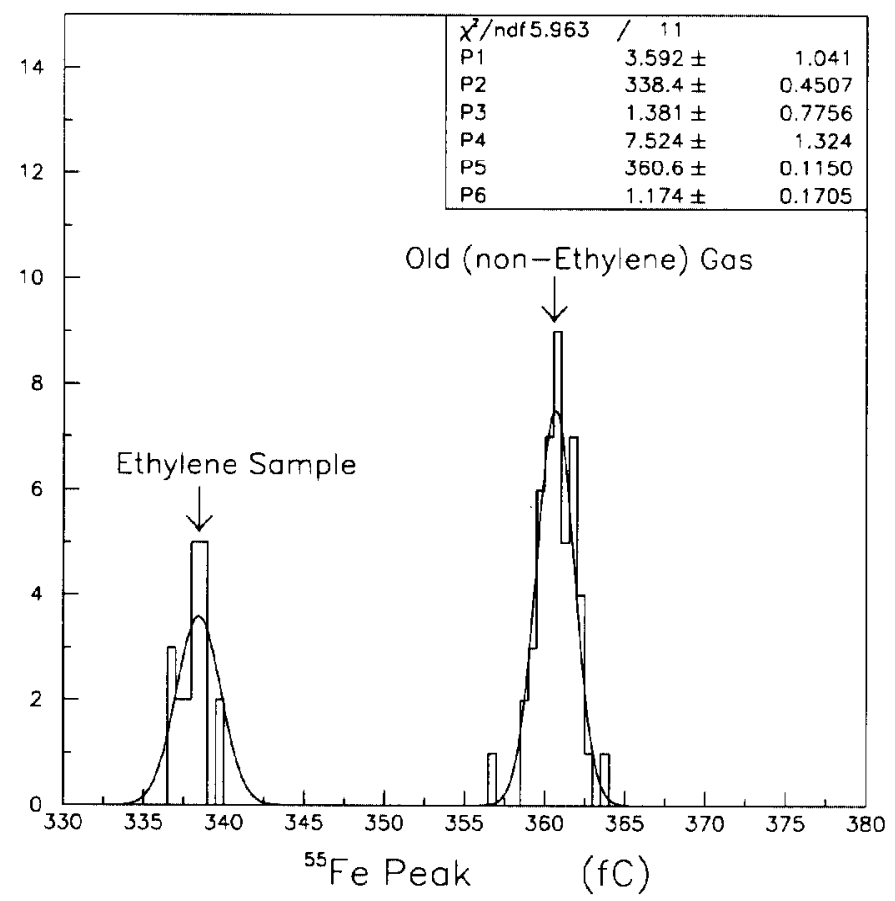

Figure 1: Gas Gain: Gain measurements of the the argon/ethane/ethylene sample, and the "old" argon/ethane mix. The addition of $1800 \mathrm{ppm}$ ethylene has shifted the gain down by $6.2 \%$.

\section{The Aging Test}

\subsection{The Test Set-Up}

The aging tests also utilized the plumbing and electronics of the Gas Quality Box system normally used to monitor the argon/ethane for the gas calorimeters[8]. The bottled gas flowed through an alcohol bubbler system using the same type of alcohol flask and refrigeration units employed for CDF gas detectors ${ }^{6}$. The gas then flowed to a proportional

${ }^{6}$ The refrigeration units were NESLAB RTE-210, and the alcohol flasks were the large $3.6 l$ flasks made by CDF. The reader should be aware that while the RTE-210's are able to maintain stable temperatures to about $0.1^{\circ} \mathrm{C}$, they suffer, as implemented within $\mathrm{CDF}$, from considerable variations in calibration. So the alcohol temperatures in this note may not exactly match those of any particular CDF detector system even thought the set temperatures may be identical. A check of the refrigerator temperature calibration is to measure the actual water-glycol temperature. For the units used in this note a $-5.0^{\circ} \mathrm{C}$ setting for the ethanol unit actually had a water-glycol temperature of $-5.7^{\circ} C$, and for the isopropyl unit a setting of $-3.0^{\circ} C$ corresponded to $-0.8^{\circ} C$ water-glycol temperature.

To further the confusion, the reader may also note that the alcohol flask is under a considerable thermal gradient between the flask walls at the coolant temperature, and the top of the flask near room temperature 
tube mounted in Gas Quality Box 1. There the temperature and pressure are controlled eliminating the need for corrections of the gain measurements due to density variations.

The proportional tubes used for the aging test were not the Brandeis tubes used for the gain measurement, but were cylindrical brass tubes (nominal dimensions: $7 / 16$ in tube with i.d. $0.405 \mathrm{in}$, wall $0.018 \mathrm{in}$ ), strung with $50 \mu \mathrm{m}$ diameter gold plated tungsten wire. The brass tube had the walls machined down in two locations to form $\approx 1 \mathrm{~cm}$ wide "windows" for irradiating the wire with sources: one spot for aging (using a ${ }^{90} \mathrm{Sr}$ source), and one as a control. Although the wall thickness was reduced to about 2 mils, the attenuation of the radiation was still quite significant so the walls were filed down further by hand.

The tube response was monitored by accumulating ${ }^{55} \mathrm{Fe}$ spectra using the readout and data taking programs of the gas gain monitoring system. The spectra (normally about 4000 triggers) are accumulated in an LSI-11 microcomputer, fit with a gaussian (over $\pm 1.5 \sigma$ ) to determine the $5.9 \mathrm{keV}$ peak position and width. The full spectra were also periodically saved as the radiation dose was increased. A decline in the peak position and growth in the width are signs that aging has taken place. The decline of the gain is monitored by forming the ratio of the average gain determined from several spectra from the aging window to the average from the control window.

Forming the ratio eliminates problems of gain shifts due to gas mix, HV reproducibility, etc.. However, drifts over short time scales remain a possible source of systematic error in this ratio. More specifically, a potential source of systematic error arises from the fact that the temperature controlled Gas Quality Box must be opened to move the ${ }^{55} F e$ source from window to window. The box is nominally controlled to about $0.1^{\circ} C$. A shift just under $0.1^{\circ} \mathrm{C}$ occurring after moving the source would be undetected and could then contribute as much as $\approx 0.25 \%$ shift in the gain. In practice, some episodes of gain instability were observed, and when identified ${ }^{7}$ the data were dropped. Some of the gain drifts were probably due to the box temperature, but the control of the alcohol temperature may also have been responsible for occasional gain drift.

The gains of the two windows were found to systematically disagree by a percent or so for these tubes. We suspect that this is a result of some deformation of the walls. This is difficult to completely eliminate given the very thin walls coupled with the need to file them down by hand. For this reason plots of the gain ratio will in general not start at 1.00. When comparing the results of different tubes on the same plot we will arbitrarily rescale the ratios so that they overlap at low doses.

(the top is insulated, but this is of limited effectiveness). The result is that the liquid alcohol is indeed at, or very near, the water-glycol temperature, but the gas layer above the liquid may be significantly warmer. This may mean that more alcohol is being absorbed in the argon/ethane than naively thought based on simple vapor pressure calculations using the water-glycol temperature. However, this is true for both our tests and the CDF gas detectors so the comparison is valid; but it does introduce a quantitative uncertainty if the results are carried over to non-CDF set-ups.

The temperatures used in the body of this note are the water-glycol temperatures, furthermore we do assume this temperature is valid for naive vapor pressure calculations when we quote the fraction of alcohol in the gas. No further attention is given to these two ambiguities in this note.

${ }^{7}$ This was suspected if the gain was drifting while collecting spectra at a particular window, without moving the source. Another test occasionally done was to cycle through the two windows for two sets of measurements, eg. running spectra at window- $A$, then $B$, and then returning again to $A$. 

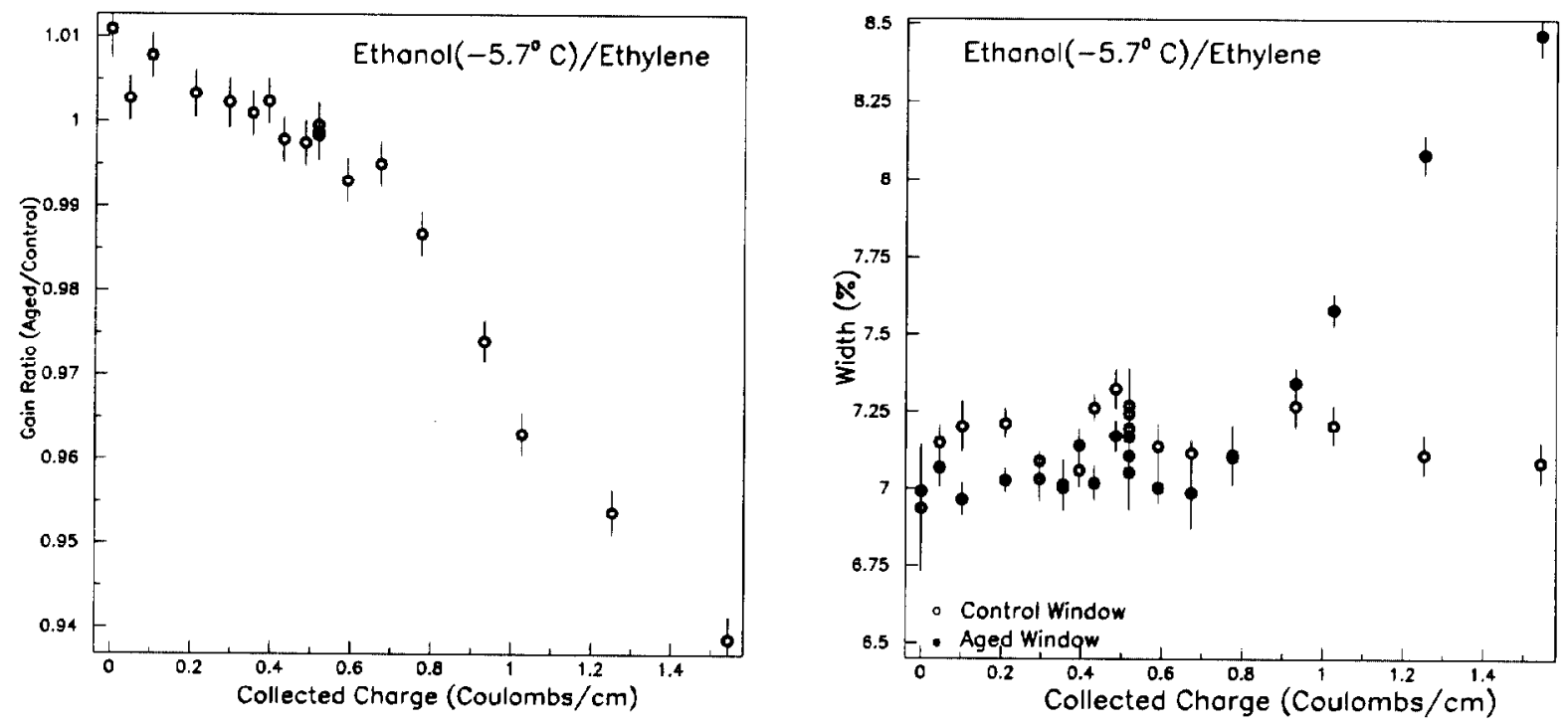

Figure 2: Ethanol Aging Test: a) The ratio of "aging window" gain to "control window" gain is plotted as a function of integrated charge per $\mathrm{cm}$; b) width of the ${ }^{55} \mathrm{Fe}$ peak for the control window and the aging window.

The amount of collected charge is determined by the amount of current drawn from the HV-supply ${ }^{8}$ and the length of time the HV was on. The current draw ranged from $\approx 0.20 \mu \mathrm{A}$ for the early measurements (with a weak ${ }^{90} \mathrm{Sr}$ source), and up to about $1.4 \mu \mathrm{A}$ for those later in a test run (e.g. after about $0.3-0.6 C$ were accumulated). Since the aging window was $1 \mathrm{~cm}$, the collected charge directly translates into Coulombs $/ \mathrm{cm}$.

\subsection{Aging Results with Ethyl Alcohol}

The ethanol tests were conducted with the alcohol bath at $-5.7^{\circ} \mathrm{C}$ (corresponding to a vapor pressure of $7.8 \mathrm{~mm} \mathrm{Hg}[9]$ or about $1 \%$ ethanol in the mix), and a flow rate of $0.05-0.1 S C F H$. The tube was run with voltages up to about $2.4 \mathrm{kV}$, around the start of the limited-streamer mode. The instantaneous current drawn at various stages of the aging test ranged from about $0.22 \mu \mathrm{A}$ in the beginning, to $1.2 \mu \mathrm{A}$ for the later measurements. The ${ }^{55} \mathrm{Fe}$ spectra were run at about $2.0 \mathrm{kV}$.

A plot of the gain ratio versus the integrated charge for the ethanol test is shown in Figure 2a. Each point is an average over several measurements. The error bars are derived from the rms spread of the measurements divided by the square root of the number of

\footnotetext{
${ }^{8}$ Droege HV supplies.
} 

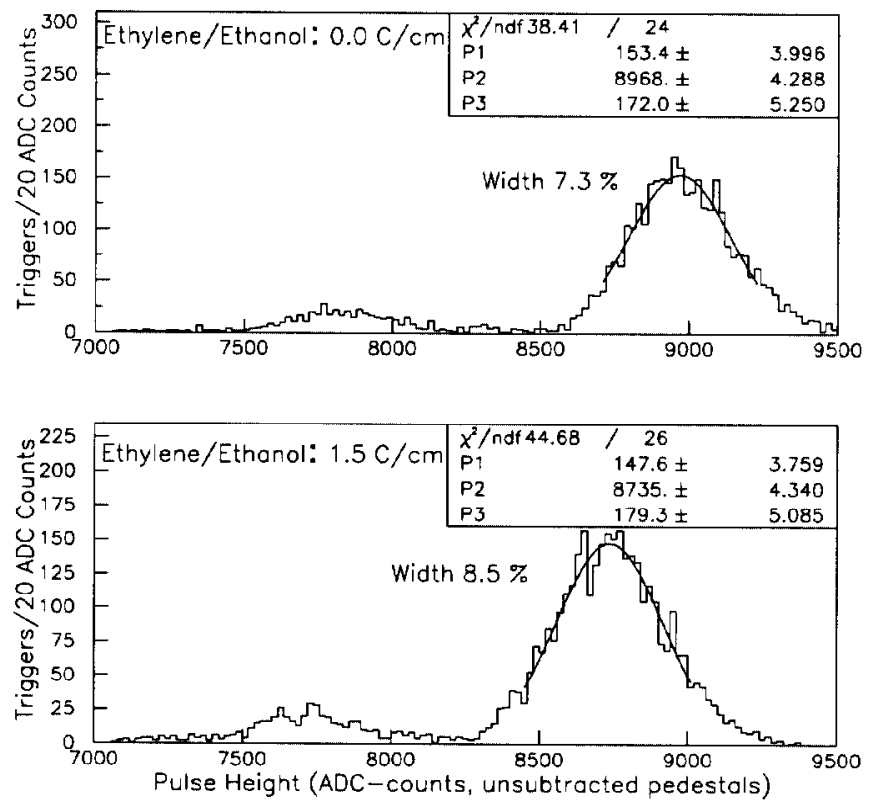

Figure 3: Ethanol Aging Test: ${ }^{55} \mathrm{Fe}$ spectrum at the beginning and end of the aging test. The peak is seen to have shifted down, but the main peak is still cleanly separated from the argon escape peak.

measurements, and combined, in quadrature, with an estimated systematic error of $0.25 \%$ (the dominant contribution). The early points less than $0.1 \mathrm{C} / \mathrm{cm}$ show quite a bit of scatter. These points probably have larger systematic errors due to start-up problems. A decline in gain is clearly occurring, but is quite gradual, less than $1 \%$ at $0.5 \mathrm{C} / \mathrm{cm}$, and $7 \%$ at $1.5 \mathrm{C} / \mathrm{cm}$.

The variation of the ${ }^{55} \mathrm{Fe}$ peak width (expressed as a percentage of the peak value) is shown in Figure 2b as a function of charge for both the aging window and the control window. As expected for aging, the width of the aging window increases as the gain decreases. The control window's width has remained constant, confirming that the control window has not undergone significant degradation.

Figure 3 shows examples of the actual spectra obtained at the beginning of the aging test and at its end. The ${ }^{55} \mathrm{Fe}$ peak is easily separated from the lower argon escape peak. Aging causes the peak to shift down and broaden, in severe cases the ${ }^{55} \mathrm{Fe}$ peak will begin to merge with the argon escape peak. The spectra for $1.5 \mathrm{C} / \mathrm{cm}$ exposure clearly shows the deterioration, but the escape peak is still cleanly separated.

After the irradiation was stopped the wire was removed from the tube and visually examined under an optical microscope. A blackened region on the wire was observed, characteristic of oxidation of the gold wire surface as was expected with argon/ethane/ethanol mixture. We did not however observe "hairs" or other signs of polymerization. 


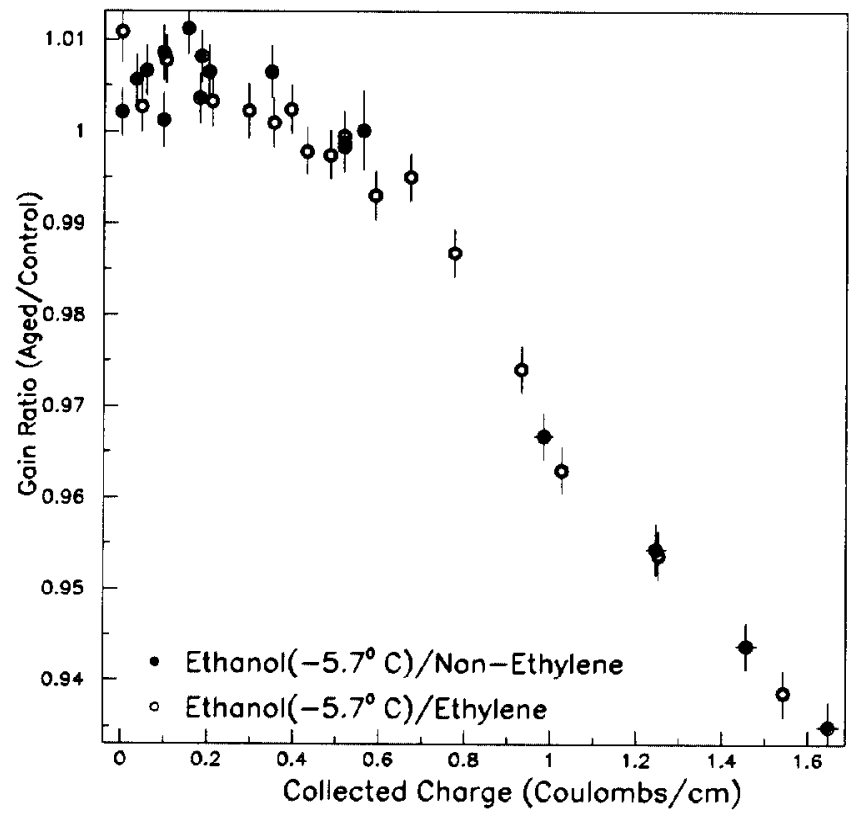

Figure 4: Ethanol Aging Test: The ratio of "aging window" gain to "control window" gain plotted as a function of integrated charge per $\mathrm{cm}$ for the original (ethylene-free) ethane supply and for the ethylene sample.

We have also run an aging test using the sample of the argon/ethane mix from the old contract (Section 2.2). The aging plot is shown in Figure 4 with the argon/ethane/ethylene data of Figure 2 superimposed (with a $1 \%$ renormalization of the non-ethylene data). The data show no difference between the ethylene and the ethylene-free samples.

\subsection{Aging Results with Isopropyl Alcohol}

The isopropyl alcohol (2-propanol) tests were conducted with the alcohol bath at $-0.8^{\circ} \mathrm{C}$ (corresponding to $7.7 \mathrm{~mm} \mathrm{Hg}$ vapor pressure[9], again about $1 \%$ isopropyl in the mix), and a flow rate of $0.05-0.1 S C F H$. The $\mathrm{HV}$ and current draw were also similar to the ethanol test.

The aging data are plotted in Figure 5, including the ethanol/ethylene data of Figure 2a. Little difference is apparent, indicating that quantitatively the aging suppression is primarily determined by the amount of alcohol rather than the specific type. A separate run of a tube with the isopropyl/ethylene-free gas was not deemed necessary in light of all the other test results. 


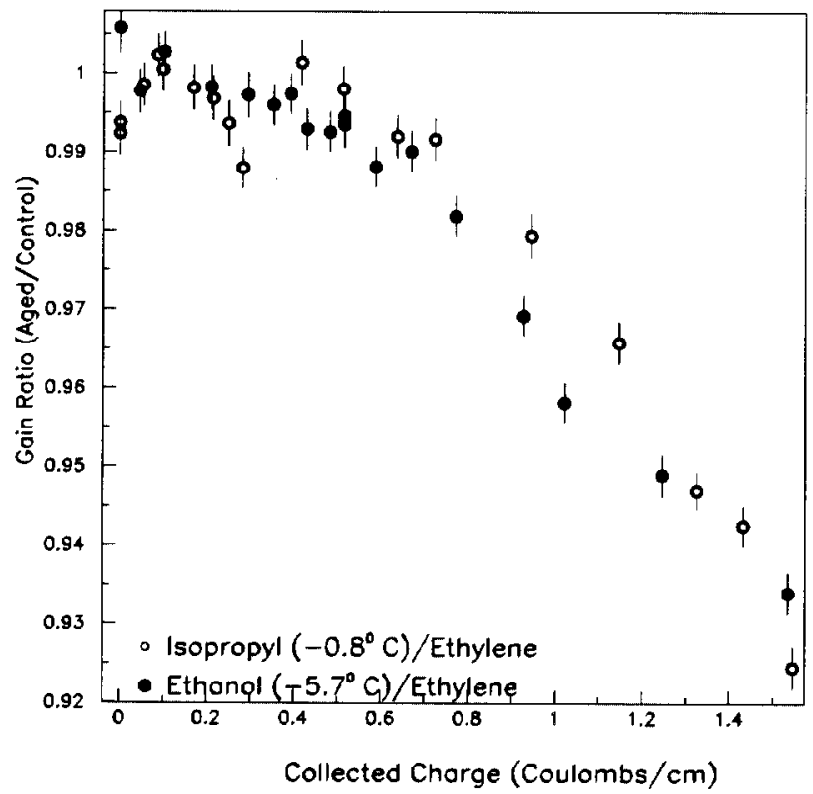

Figure 5: Isopropyl Aging Test: The ratio of "aging window" gain to "control window" gain is plotted as a function of integrated charge per $\mathrm{cm}$ for the $-0.8^{\circ} \mathrm{C}$ isopropyl and the $-5.7^{\circ} \mathrm{C}$ ethanol tubes.

\subsection{Aging Results Without Alcohol}

Given that the presence of ethylene did not show any difference in the deterioration of the wire in the ethanol test, it is natural to ask whether the ethylene makes any difference at all, i.e. even without any alcohol? To check this, measurements were made with the argon/ethane/ethylene mix, and another with the "old" ethylene-free gas.

The operational parameters were similar to the other tests, except that due to the more rapid aging it was not necessary to operate with the hotter ${ }^{90} \mathrm{Sr}$ source. Therefore the entire test was run at about $2.4 \mathrm{kV}$ and the current draw never exceeded $0.24 \mu \mathrm{A}$. The results are shown in Figure 6. The wires age, as expected, much faster without any alcohol present[2]; but clearly the presence of $1800 \mathrm{ppm}$ ethylene has not made a significant difference. The wires from these two tubes were also removed and examined under an optical microscope. Only a very slight darkening of the wire was observed, as expected from minor oxidation of the wire.

It is in fact not very surprising that we do not see any difference with and without alcohol in our well controlled and clean environment with brass tubing and gold plated wire. As shown by several papers in the 1986 Workshop on Radiation Damage to Wire 


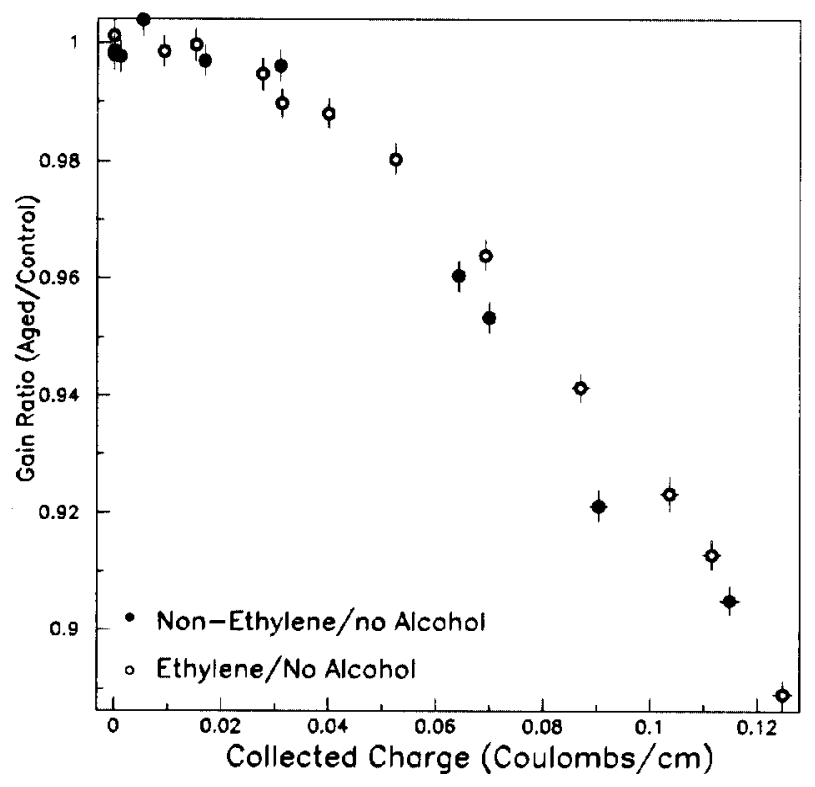

Figure 6: Non-alcohol Aging Test: The ratio of "aging window" gain to "control window" gain is plotted as a function of integrated charge per $\mathrm{cm}$. The results for the $1800 \mathrm{ppm}$ argon/ethane/ethylene mix, and the "old" non-ethylene mix.

Chambers[11] aging by polymerization requires the presence of free radicals. The formation of such radicals from $C_{2} H_{6}$ is unlikely under the normal proportional chamber operations (the concentration of $\mathrm{CH}_{4}$ and $\mathrm{C}_{2} \mathrm{H}_{4}$ are small in any case). The aging due to corrosion by the dissociation of ethane or ethanol will not readily occur due to the usage of gold plated tungsten anode wire and the brass tube. Gold plating will greatly reduce oxidation; and since copper oxide is a semiconductor it will not effect the electric field[2].

\section{Conclusions}

We have run a number of aging tests with various permutations of alcohol and ethylene present in an argon/ethane mix. The deterioration of the wires is seen to be quite modest in the presence of alcohol: about $6 \%$ gain drop out to $\approx 1 \mathrm{C} / \mathrm{cm}$. Although it has a different geometry, we note as a figure of merit that it is estimated that Super Layer 0 of the CTC accumulates $0.38 \mathrm{C} / \mathrm{cm}-s w / \mathrm{fb}^{-1}[12]^{*}$. Furthermore the ethylene contamination of a few thousand parts per million in ethane does not increase the deterioration of the wires, irrespective of the addition of alcohol.

* sw $=$ sense wire 
The small amount of ethylene impurity, much less than $1 \%$, may not effect the aging due to the fact that the electrons in the avalanche are mainly produced from argon by impact ionization, with the electrons gaining sufficient kinetic energies under the electric field. The photodissociation of ethylene will also be minor due to the fact that there is less than a $1 \%$ chance of the UV photons finding an ethylene molecule in the swarm of ethane molecules. Therefore one would have expected that small levels of ethylene impurities would not appreciably contribute to the aging processes unless they were several orders of magnitude more effective in causing such deterioration.

We conclude that a relaxation of CDF's contract specifications (Appendix B) of the ethylene content in the ethane would not noticeably alter detector life spans. However, accepting ethylene levels approaching that of these tests would cause significant gain shifts for the gas calorimeters, and perhaps have a noticeable impact on drift velocities and/or angles. ${ }^{9}$ Such changes could likely be accommodated, but significant variations of the ethylene content from trailer to trailer would make it more difficult to maintain the stability of the calibrations. A decision to accept significant levels of ethylene should also take into account the impact on detector calibrations.

\section{Acknowledgements}

We would like to thank Jack Layman for the prompt and delicate machining of the tubes and a second mounting chamber; and Don Mizicko and his crew for technical assistance with the gas supplies and the mechanical set-up.

\section{References}

[1] D. Mizicko, private communication.

[2] M.Atac, IEEE Trans. on Nuclear Sci. Vol.NS-31, No.1 (1984) 99.

[3] H. Kobayashi et. al., Macromolecules 7 (1974) 277.

[4] Great Lakes Airgas, Chicago, IL.

[5] National Draeger, Inc., Dräger Detector Tube Handbook, 8th ed, National Draeger, Inc./Drägerwerk Aktiengesellschaft Lübeck, 1992.

[6] C. Snyder, ANL Chemistry Laboratory Report on Sample 94-0255-01, June 3, 1994.

[7] C. Snyder, ANL Chemistry Laboratory Report on Sample 94-0245-02, May 4, 1994.

[8] G. Bauer, et. al., The Gas Gain System for Run Ia (1992-3), CDF 2591, May 1994; G. Bauer, et. al., The Gas Gain System for Run Ib, in preparation.

[9] CRC Handbook of Chemistry and Physics, 73-rd Edition, CRC Press 1992-93.

\footnotetext{
${ }^{9} \mathrm{~A}$ study of the effect of ethylene on drift velocities and angles is foreseen.
} 
[10] R.B. Bird, W.E. Stewart, and E.N. Lightfoot, Transport Phenomena, John Wiley and Sons, 1960.

[11] Proceedings of the Workshop on Radiation Damage to Wire Chambers, J. Kadyk, ed, LBL, April 1986, LBL-21170.

[12] R. Wagner, private communication. 


\section{A Compositional Analyses}

Table 1a. Airgas analysis[4] of ethane/ethylene sample (measured by gas chromatograph).

\begin{tabular}{|c|c|}
\hline \hline Substance & Volume Percent \\
\hline \hline $\mathrm{CH}_{4}$ & 0.005 \\
$\mathrm{H}_{2} \mathrm{O}$ & 0.001 \\
$\mathrm{CO}$ & Not Detected \\
$\mathrm{C}_{2} \mathrm{H}_{4}$ & 0.274 \\
$\mathrm{Air}$ & 0.004 \\
$\mathrm{CO}_{2}$ & Not Detected \\
$\mathrm{C}_{3} \mathrm{H}_{6}$ & 0.04 \\
$\mathrm{C}_{3} \mathrm{H}_{8}$ & 0.01 \\
\hline
\end{tabular}

Table 1b. Argonne mass spectroscopic analysis $[6]$ of the Airgas ethane/ethylene sample. Note: This analysis is based on selected list of substances, it is not an exhaustive search for trace contaminants.

\begin{tabular}{|c|c|}
\hline \hline Substance & Volume Percent \\
\hline \hline $\mathrm{H}_{2}$ & $<0.015^{*}$ \\
$\mathrm{CH}_{4}$ & $<0.004^{*}$ \\
$\mathrm{H}_{2} \mathrm{O}$ & $<0.02$ \\
$\mathrm{CO}$ & $<0.009^{*}$ \\
$\mathrm{~N}_{2}$ & $<0.004^{*}$ \\
$\mathrm{C}_{2} \mathrm{H}_{6}$ & $99.9 \pm 0.1$ \\
$\mathrm{O}_{2}$ & $0.019 \pm 0.002$ \\
$\mathrm{H}_{2} \mathrm{~S}$ & $<0.01^{*}$ \\
$\mathrm{Ar}$ & $0.0074 \pm 0.0015$ \\
$\mathrm{CO}_{2}$ & $0.0014 \pm 0.0003$ \\
$\mathrm{C}_{3} \mathrm{H}_{8}$ & $0.0122 \pm 0.0024$ \\
\hline \multicolumn{2}{|c|}{ Detection Limit } \\
\hline
\end{tabular}


Table 2. Argonne mass spectroscopic analysis[7] of Trailer \# 388. Note: This analysis is based on selected list of substances, it is not an exhaustive search for trace contaminants.

\begin{tabular}{|c|c|}
\hline \hline Substance & Volume Percent \\
\hline \hline $\mathrm{H}_{2}$ & $<0.015^{*}$ \\
$\mathrm{CH}_{4}$ & $<0.004^{*}$ \\
$\mathrm{H}_{2} \mathrm{O}$ & $<0.03$ \\
$\mathrm{CO}$ & $<0.009^{*}$ \\
$\mathrm{~N}_{2}$ & $<0.004^{*}$ \\
$\mathrm{C}_{2} \mathrm{H}_{6}$ & $99.9 \pm 0.2$ \\
$\mathrm{O}_{2}$ & $<0.05$ \\
$\mathrm{H}_{2} \mathrm{~S}$ & $<0.01^{*}$ \\
$\mathrm{Ar}$ & $<0.005$ \\
$\mathrm{CO}_{2}$ & $<0.001$ \\
$\mathrm{C}_{3} \mathrm{H}_{8}$ & $<0.008^{*}$ \\
\hline \multicolumn{2}{|c|}{ Detection Limit } \\
\hline
\end{tabular}

\section{B Ethane Specifications}

Table 3. Contract specifications for upper limits of contaminants in the ethane supply prior to June 1994 [1].

\begin{tabular}{|c|c|}
\hline \hline Substance & Upper limits \\
\hline \hline $\mathrm{H}_{2}$ & $10 p p m$ \\
$\mathrm{CH}_{4}$ & $1.0 \%$ \\
$\mathrm{H}_{2} \mathrm{O}$ & $10 \mathrm{ppm}$ \\
$\mathrm{N}_{2}$ & $0.1 \%$ \\
$\mathrm{C}_{2} \mathrm{H}_{4}$ & $20 \mathrm{ppm}$ \\
$\mathrm{O}_{2}$ & $10 \mathrm{ppm}$ \\
$\mathrm{H}_{2} \mathrm{~S}$ & $10 \mathrm{ppm}$ \\
$\mathrm{CO}_{2}$ & $0.1 \%$ \\
$\mathrm{C}_{3} \mathrm{H}_{8}$ & $1.0 \%$ \\
$\mathrm{Halogens}$ & $10 \mathrm{ppm}$ \\
Total Impurities & $1.0 \%$ \\
\hline
\end{tabular}


Table 4. New contract specifications for limits on contaminants for ethane since June 1994 [1]. There are two options, "With" or "Without" ethylene.

\begin{tabular}{|c|c|c|}
\hline \hline Substance & "With" & "Without" \\
\hline \hline $\mathrm{H}_{2}$ & $10 p p m$ & $10 p p m$ \\
$\mathrm{CH}_{4}$ & $0.5 \%$ & $0.5 \%$ \\
$\mathrm{H}_{2} \mathrm{O}$ & $10 p p m$ & $10 p p m$ \\
$\mathrm{~N}_{2}$ & $0.1 \%$ & $0.1 \%$ \\
$\mathrm{CO}$ & $0.1 \%$ & $0.1 \%$ \\
$\mathrm{C}_{\mathbf{2}} \mathrm{H}_{4}$ & $1600 \mathrm{ppm}$ & $\mathbf{2 0} \mathrm{ppm}$ \\
$\mathrm{O}_{2}$ & $10 \mathrm{ppm}$ & $10 \mathrm{ppm}$ \\
$\mathrm{H}_{2} \mathrm{~S}$ & $10 \mathrm{ppm}$ & $10 \mathrm{ppm}$ \\
$\mathrm{CO}_{2}$ & $0.1 \%$ & $0.1 \%$ \\
$\mathrm{C}_{3} \mathrm{H}_{8}$ & $0.1 \%$ & $0.1 \%$ \\
Halogens & $10 \mathrm{ppm}$ & $10 \mathrm{ppm}$ \\
Total Impurities & $1.0 \%$ & $1.0 \%$ \\
\hline
\end{tabular}

